DOI: $10.33764 / 2687-041 X-2021-1-133-139$

\title{
ОПЫТ РАБОТ ПО ЗОНИРОВАНИЮ Д. УРГУН ИСКИТИМСКОГО РАЙОНА НОВОСИБИРСКОЙ ОБЛАСТИ
}

\section{Татьяна Александровна Беклемищева}

Сибирский государственный университет геосистем и технологий, 630108, Россия, г. Новосибирск, ул. Плахотного, 10, обучающийся, тел. (999)462-45-50, e-mail: beklemisheva299@mail.ru

\section{Анатолий Викторович Ериов}

Сибирский государственный университет геосистем и технологий, 630108, Россия, г. Новосибирск, ул. Плахотного, 10, кандидат технических наук, доцент кафедры кадастра и территориального планирования, тел. (961)845-44-09, e-mail: er-tos@inbox.ru

В статье рассмотрен процесс зонирования территории деревни Ургун с использованием геоинформационной системы MapInfo Professional. Описан процесс зонирования территории по целевому назначению и по виду разрешенного использования земель. Также в статье дана краткая характеристика району работ, приведены теоретические сведения о зонировании территорий.

Ключевые слова: зонирование территорий, функциональное зонирование, вид разрешенного использования, целевое назначение

\section{EXPERIENCE IN ZONING THE VILLAGE OF URGUN IN ISKITIM DISTRICT OF NOVOSIBIRSK REGION}

\section{Tatyana A. Beklemishcheva}

Siberian State University of Geosystems and Technologies, 10, Plakhotnogo St., Novosibirsk, 630108, Russia, Student, phone: (999)462-45-50, e-mail: beklemisheva299@mail.ru

\section{Anatoly V. Ershov}

Siberian State University of Geosystems and Technologies, 10, Plakhotnogo St., Novosibirsk, 630108, Russia, Ph. D., Associate Professor, Department of Cadastre and Territorial Planning, phone: (961)845-44-09, e-mail: er-tos@inbox.ru

The article describes the process of zoning of the territory of the village of Urgun using the MapInfo Professional geoinformation system. Zoning of the territory was carried out according to the intended purpose and type of permitted land use. The article also provides a brief description of the area of work and provides theoretical information about zoning of territories.

Keywords: zoning of territories, functional zoning, type of permitted use, intended purpose

Зонирование территории представляет собой разграничение этой территории с выделением особых зон. Для каждой из зон определяется целевое назначение, приоритетные функции и режимы ее использования.

Функциональное зонирование - разграничение территории на зоны в процессе градостроительного планирования развития территории. Функциональное зонирование определяет функциональное назначение этой территории [1]. 
Основой функционального зонирования являются схемы землеустройства, схемы использования и охраны земельных ресурсов, землеустроительные, градостроительные, природоохранные нормативно-правовые акты и иная документация. Вопросы зонирования территорий населенных пунктов регулируются Земельным и Градостроительным кодексами РФ $[1,2]$.

Решение о проведении зонирования территории принимается местными органами исполнительной власти и осуществляется за счет бюджетных средств.

Деревня Ургун расположена в Евсинском сельсовете. Муниципальное образование Евсинский сельсовет входит в состав Искитимского муниципального района Новосибирской области и занимает площадь 15581,00 га. Границы Евсинского сельсовета установлены законом Новосибирской области от 02.06.2004 № 200-О3 «О статусе и границах муниципальных образований Новосибирской области» с последующими изменениями и дополнениями [3].

На территории сельсовета находятся три населенных пункта: станция Евсино (административный центр), деревня Ургун и деревня Шадрино [4]. Площадь деревни Ургун составляет 123 га. Численность населения деревни Ургун на 01 января 2019 года составляла 920 человек.

Главной планировочной осью территории сельсовета является автомобильная дорога федерального значения Р-256 «Чуйский тракт» Новосибирск Барнаул - Горно-Алтайск - граница с Монголией.

Зонирование деревни Ургун выполнялось на основе цифровых спутниковых снимков общего пользования, растровых изображений (топографических карт) и ортофотопланов на территорию Искитимского района Новосибирской области масштаба 1:2000-1:25000, выгрузки данных с публичной кадастровой карты Росреестра (рис. 1) и данных электронных картографических справочников $[5,6]$.

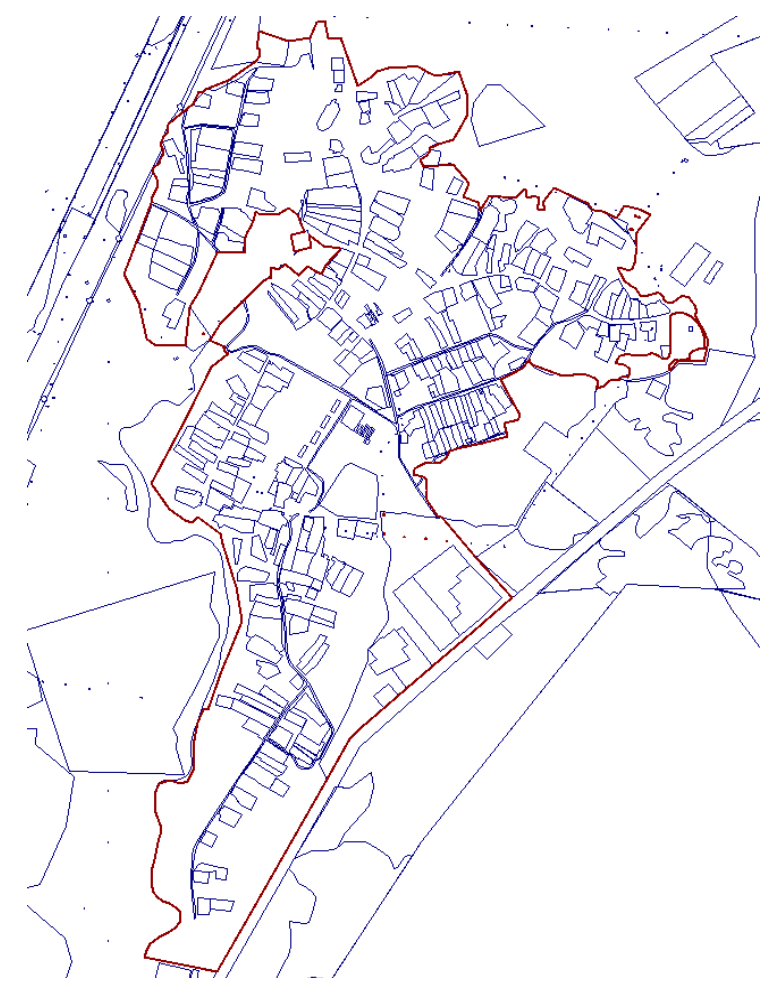

Рис. 1. Кадастровое деление территории д. Ургун 
На первом этапе было проведено зонирование территории по целевому назначению. Целевое назначение представляет собой деление земель и земельных участков Российской Федерации по категориям и назначению использования [2].

Для каждого отдельного участка было установлено к какой категории земель он относится (рис. 2).

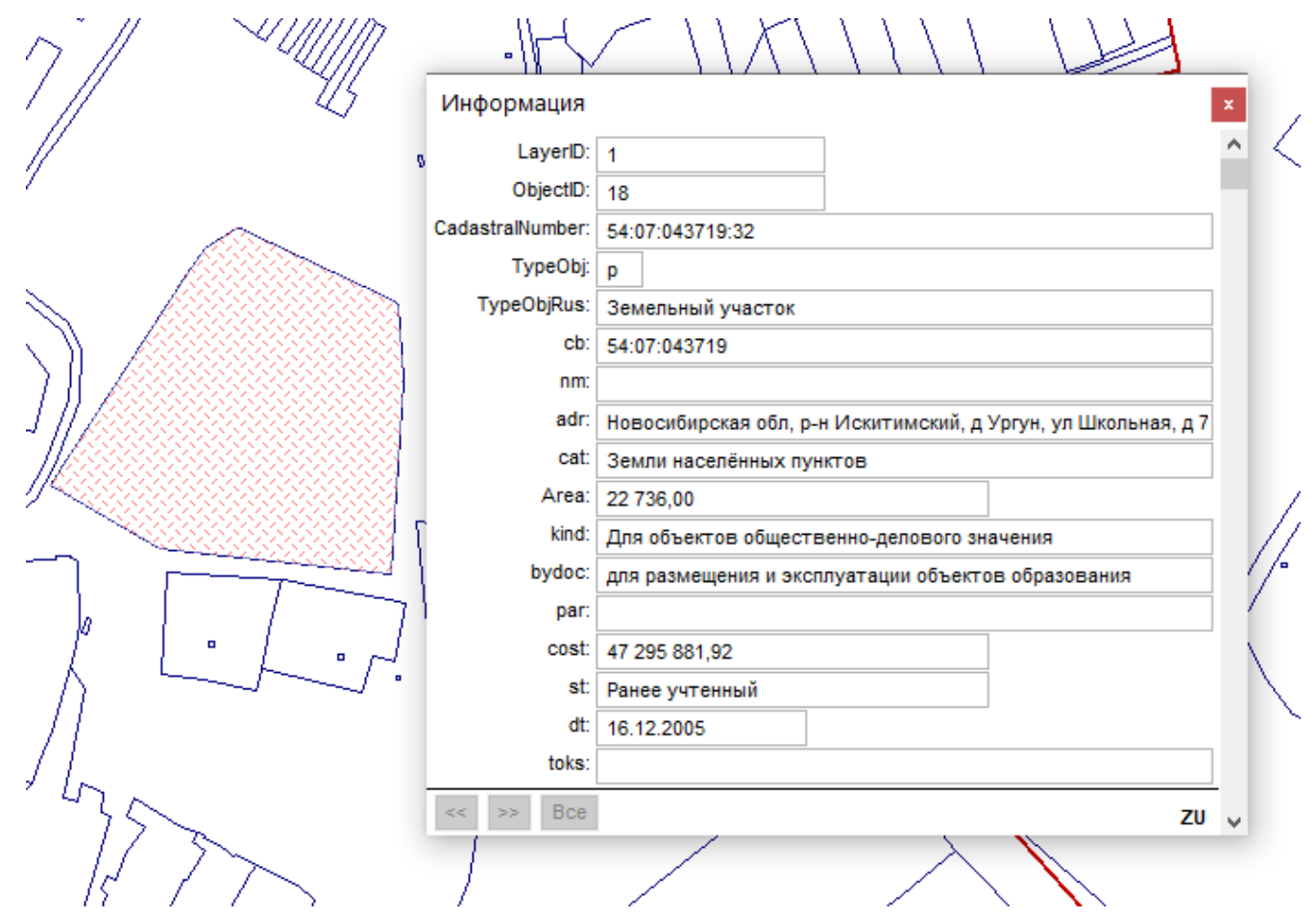

Рис. 2. Процесс деления земельных участков по категориям земель

Все участки были объединены по категориям земель и сгруппированы в отдельный слой [7]. В соответствии с условными обозначениями (рис. 3) была подготовлена схема зонирования территории деревни Ургун по целевому назначению (рис. 4).
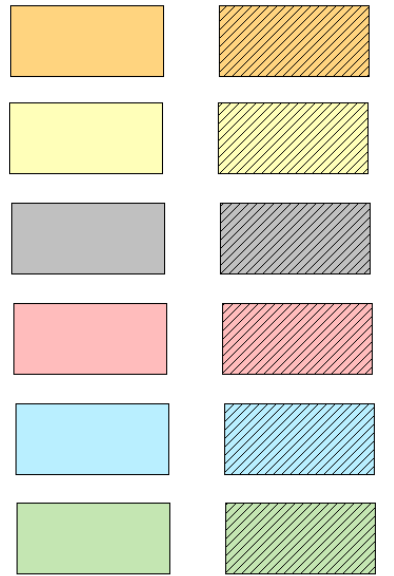

- Земли населенных пунктов

- Земли сельскохозяйственного назначения

- Земли промышленности, энергетики, транспорта, связи, радиовешания, телевидения, информатики, земли для обеспечения космической деятельности, земли обороны, безопасности и земли иного специального назначения

- Земли особо охраняемых территорий и объектов

- Земли водного фонда

- Земли лесного фонда

Рис. 3. Условные обозначения на схеме зонирования территории по целевому назначению 


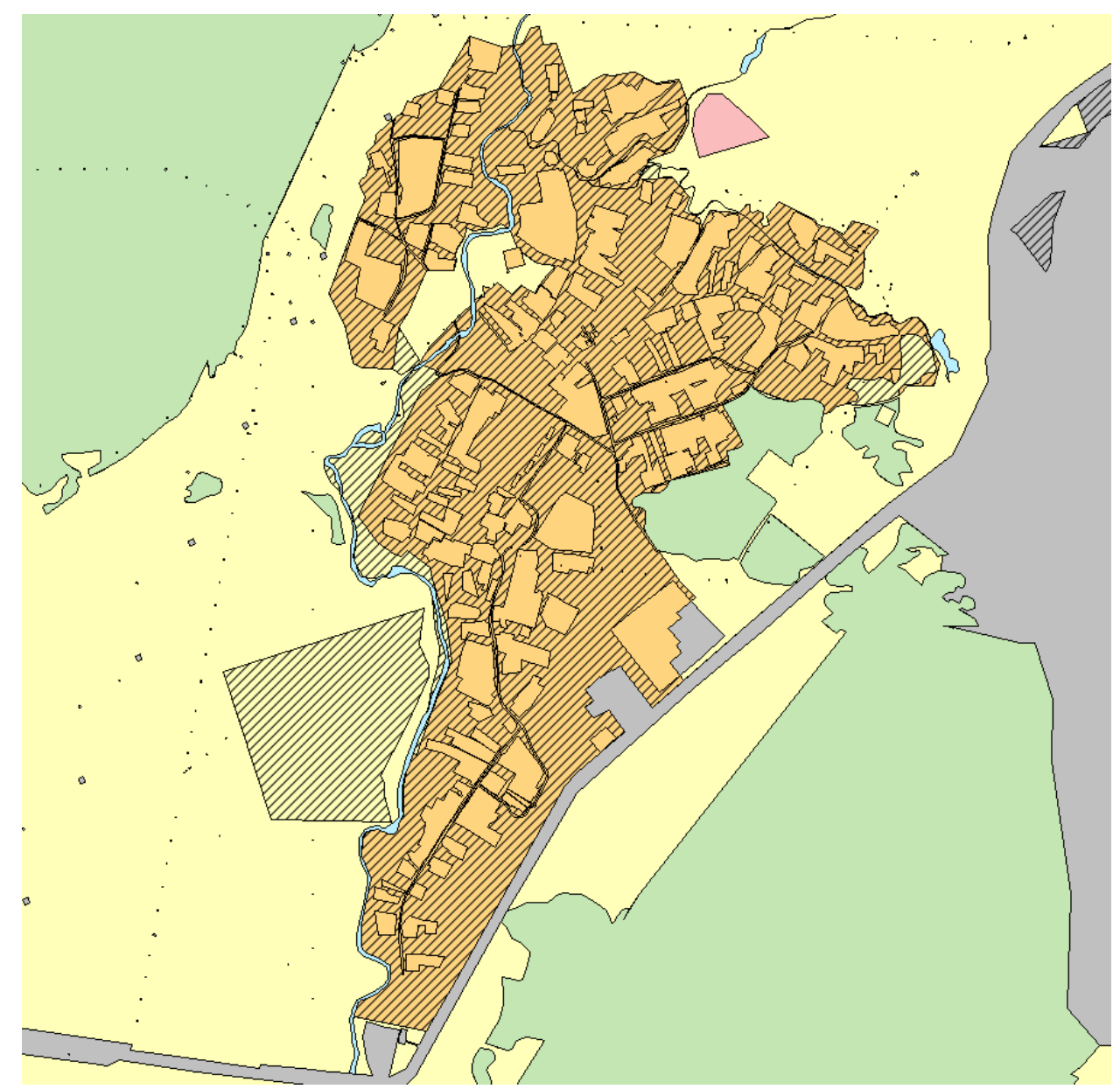

Рис. 4. Зонирование территории д. Ургун по целевому назначению

Графическое отображение и описание участков выполнено в соответствии с требованиями приказа Министерства экономического развития Российской Федерации от 9 января 2018 г. № 10 «Об утверждении Требований к описанию и отображению в документах территориального планирования объектов федерального значения, объектов регионального значения, объектов местного значения и о признании утратившим силу приказа Минэкономразвития России от 7 декабря 2016 г. № 7932» [8].

Далее было выполнено зонирование территории по видам разрешенного использования земельных участков. Вид разрешенного использования подразумевает под собой вид деятельности, для реализации которой может быть использован данный земельный участок и расположенные на нем объекты [9].

Виды разрешенного использования устанавливаются в соответствии с классификатором, утвержденным приказом Министерства экономического развития РФ от 1 сентября 2014 г. № 540 «Об утверждении классификатора видов разрешенного использования земельных участков» [10].

Аналогично предыдущему этапу, для каждого земельного участка был установлен вид разрешенного использования. Все участки были сгруппированы в отдельный слой, а участки, имеющие одинаковый вид разрешенного исполь- 
зования, были объединены между собой и отображены в соответствии с упомянутыми выше требованиями приказа Министерства экономического развития Российской Федерации от 9 января 2018 г. № 10. Результатом проделанной работы стала схема зонирования территории д. Ургун по видам разрешенного использования (рис. 5) выполненная в соответствии с условными обозначениями (рис. 6) [8].

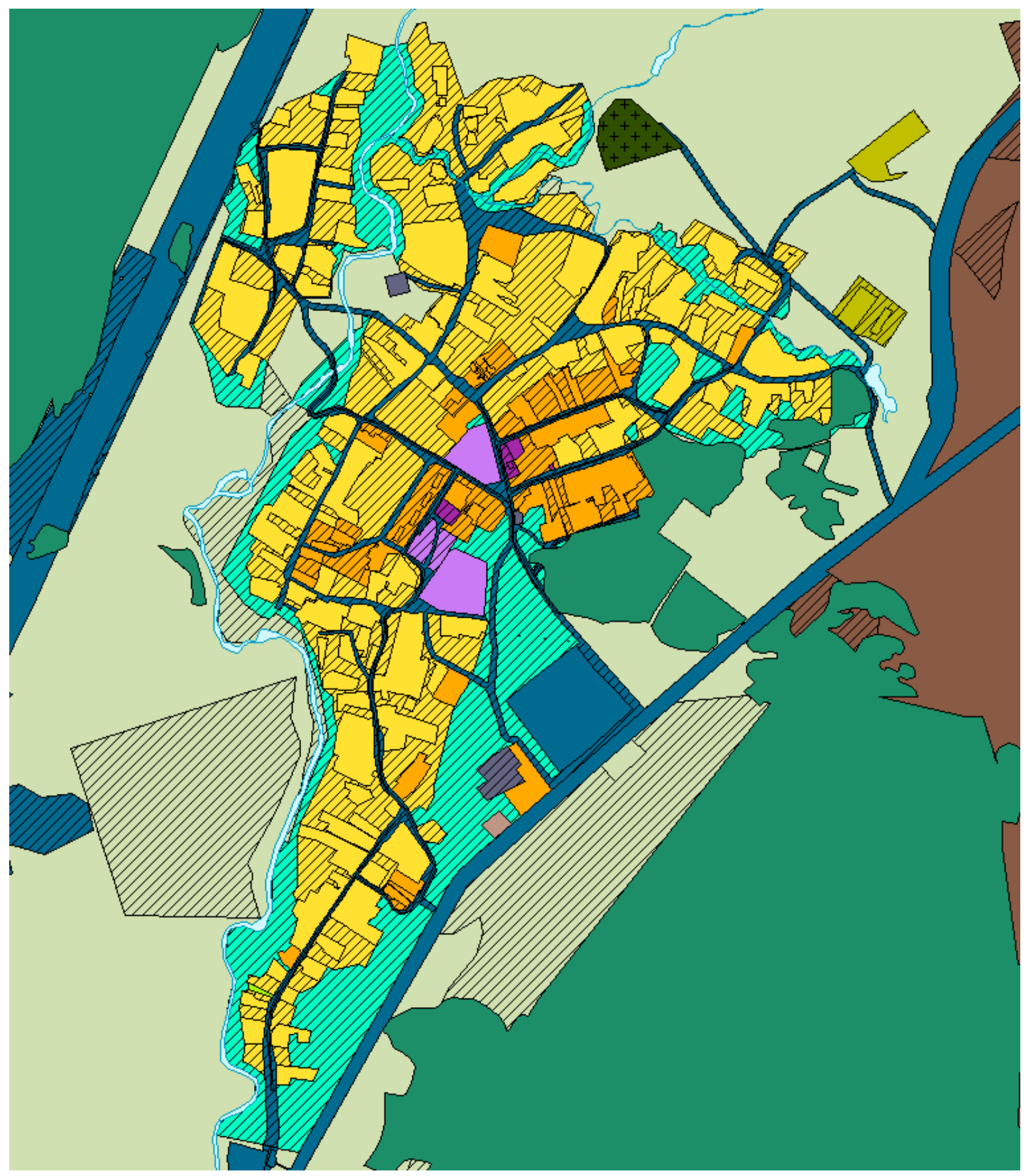

Рис. 5. Зонирование д. Ургун по видам разрешенного использования 
Жилые зоны:

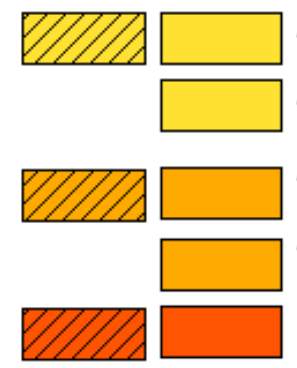

- зона застройки индивидуальными жилыми домами

- зона застройки индивидуальными жилыми домами, не вошедшая в границу населенного пункта

- зона застройки малоэтажнымп жилыми домами (до 4

этажей, включая мансардный)

- зона застройки малоэтажными жилыми домами (до 4

этажей, включая мансардный), не вошедшая в гранццу населенного пункта

- зона застройки среднеэтажными жилыми домами (от 5 до 8

этажей, включая мансардный)

Общественно-деловые зоны:
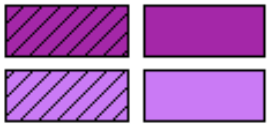

- многофункциональная общественно-деловая зона

- зона специализгрованной общественной застройки

Производственные зоны, зоны инженерной

и транспортной инфраструктуры:

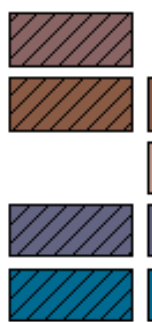

- производственная зона, зона инженерной и транспортной

инфраструктур

- производственная зона

- коммунально-складская зона

- зона инженерной инфраструктуры

- зона транспортной пнфраструктуры

Зоны сельскохозяйственного использования:

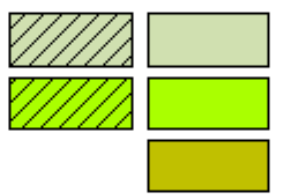

- зона сельскохозяйственных угодий

-зона садоводческих или огороднических некоммерческих товариществ

- производственная зона сельскохозяйственных

предприятий

Зоны рекреационного назначения:

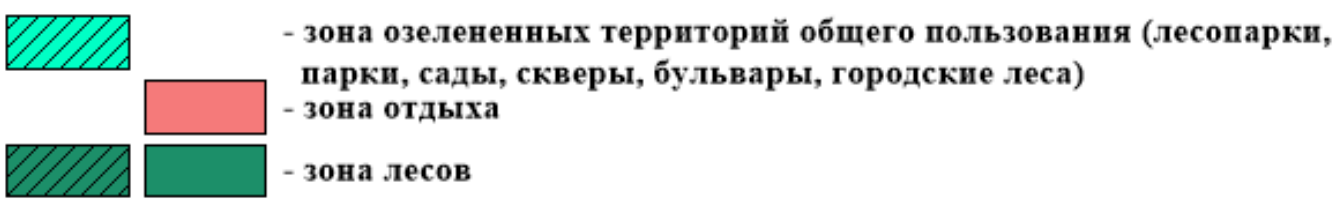

Зоны специального назначения:

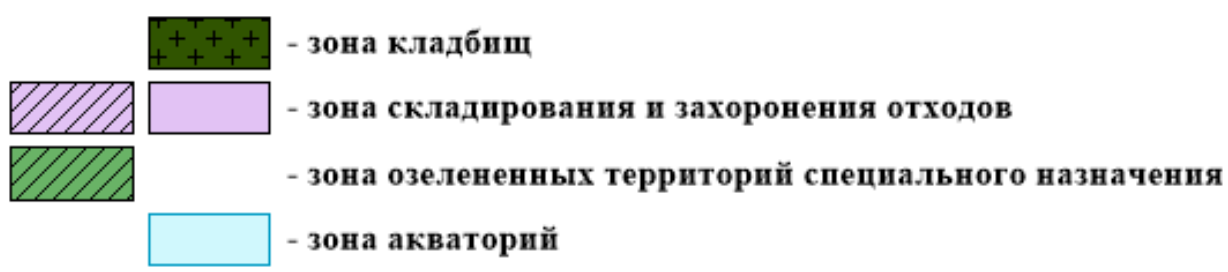

Рис. 6. Условные обозначения на схеме зонирования д. Ургун по видам разрешенного использования

Подготовленные в процессе работы схемы зонирования деревни Ургун могут послужить основой для дальнейшей работы по созданию программ и планов развития данной территории, например, для создания генерального плана. Также полученные материалы могут стать основой для создания таких карто- 
графических материалов, как карты современного использования территории, карты функциональных зон поселения, карты размещения объектов местного значения и других.

\section{БИБЛИОГРАФИЧЕСКИЙ СПИСОК}

1.Градостроительный кодекс Российской Федерации от 29.12.2004 № 190-Ф3 [Электронный ресурс]. - Режим доступа: http://www.consultant.ru/document/cons_doc_LAW_51040/.

2. Земельный кодекс Российской Федерации от 25.10.2001 N 136-ФЗ сурс]. - Режим доступа: http://www.consultant.ru/document/Cons_doc_LAW_33773/.

3. Закон Новосибирской области от 02.06.2004 № 200-О3 «О статусе и границах муниципальных образований Новосибирской области» [Электронный ресурс]. - Режим доступа: http://docs.cntd.ru/document/5415546.

4. Закон Новосибирской области от 16.03.2006 № 4-О3 «Об административнотерриториальном устройстве Новосибирской области» [Электронный ресурс]. - Режим доступа: https://novosibirsk-pravo.ru/zakon/2006-03-16-n-4-oz/.

5. Публичная кадастровая карта вам в помощь [Электронный ресурс]. - Режим доступа: https://rosreestr.ru/site/press/news/68-publichnaya-kadastrovaya-karta-vam-vpomoshch/?contrast=N/.

6. Портал услуг «Публичная кадастровая карта» [Электронный ресурс]. - Режим доступа: https://pkk.rosreestr.ru/.

7. MapInfoProfessional. Версия 8.5. Руководство пользователя [Электронный ресурс]. Режим доступа: https://mapbasic.ru/soft/8.5/MI_UG.pdf.

8. Приказ Министерства экономического развития Российской федерации от 9 января 2018 г. № 10 «Об утверждении Требований к описанию и отображению в документах территориального планирования объектов федерального значения, объектов регионального значения, объектов местного значения и о признании утратившим силу приказа Минэкономразвития России от 7 декабря 2016 г. № 7932» [Электронный ресурс]. - Режим доступа: https://www.garant.ru/products/ipo/prime/doc/71756140/.

9. Выбор вида разрешенного использования земельного участка [Электронный ресурс]. Режим доступа: https://rosreestr.gov.ru/site/press/news/vybor-vida-razreshennogo-ispolzovaniyazemelnogo-uchastka/.

10. Приказ Министерства экономического развития РФ от 1 сентября 2014 г. № 540 «Об утверждении классификатора видов разрешенного использования земельных участков» [Электронный ресурс]. - Режим доступа: https://base.garant.ru/70736874/.

(C) T. А. Беклемищева, А. В. Ершов, 2021 